fallen from space and reached Earth's surface - provide valuable insights into everything from the history of the Solar System to the identity of asteroids that could potentially collide with Earth. Snagging such objects is "the one chance you get to see Solar System material in your hands", says David Clark, who studies meteors at the University of Western Ontario in London, Canada. "We simply don't have enough of this stuff.'

\section{FIRE IN THE SKY}

Especially prized are meteorites that were tracked on their inward journey. Scientists can use data about the journey to reconstruct the object's trajectory and reveal where in the Solar System it came from. People manage to retrieve just one to three meteorites with known trajectories each year, says Peter Jenniskens, an astronomer at the SETI Institute in Mountain View, California.

FRIPON's organizers dream of collecting one tracked meteorite per year from the French landscape. By comparison, researchers with the large and dense Spanish Meteor Network have scored 2 in the past 12 years.

The French network's cameras are very densely and evenly spaced, sitting roughly 70-80 kilometres apart at laboratories, science museums and other buildings close enough together to yield good information about where meteorites land. "That increases your chance of finding something," says Jenniskens.

FRIPON is also the first fully connected and automated network, says principal investigator François Colas, of the Paris Observatory.

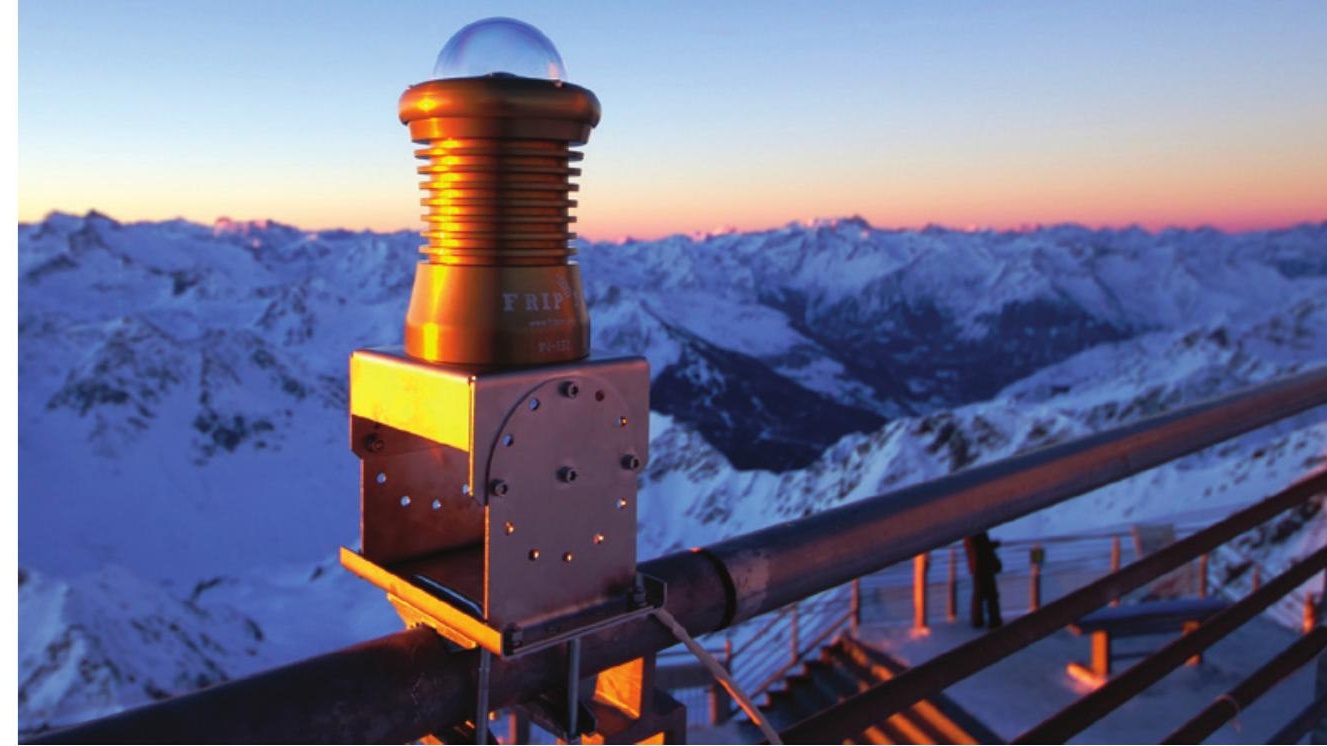

Fisheye cameras will cover France as part of the meteor-spotting network.

When a camera detects a meteor, it sends a message to a central computer in Paris. If two or more cameras spot the fireball, FRIPON scientists receive an e-mail describing where it was seen. Eventually, the e-mail will include automatically generated information about the object's probable landing zone, pinpointing it to an area roughly 1 kilometre by 10 kilometres.

The researchers will then face the arduous job of searching this area to find the object. At first, scientists will conduct the ground searches. But in the next few years, FRIPON organizers plan to train an army of citizen scientists to walk the French landscape looking for bits of meteorite - and to hand over any finds.

Perhaps one in 1,000 volunteers will actually turn up for a search, estimates Brigitte Zanda, a meteorite specialist at the National Museum of Natural History in Paris, who heads the volunteer effort. Organizers hope to field a search team of 30 people in every part of France, so they will have to recruit hundreds of thousands of people, she says. "It's ambitious." But hundreds of people have already signed up, even though the official recruitment drive is just getting under way.

\title{
Gene therapies pose million-dollar conundrum
}

\section{Economists, investors and medical insurers can't work out how to pay for cutting-edge drugs.}

\section{BY ERIKA CHECK HAYDEN}

$\mathrm{D}$ rugs that act by modifying a patient's genes are close to approval in the United States, and one is already available in Europe. The developments mark a triumph for the field of gene therapy, once considered controversial.

But with estimated price tags of at least US\$1 million per patient, how will anyone pay for these treatments? The question is just one in a broader debate about how to finance a range of super-expensive drugs that are now available, thanks to an explosion in genetic and molecular-biology research over the past 20 years.

"Advances in science are presenting a social affordability question like never before," says economist Mark Trusheim at the Massachusetts Institute of Technology in Cambridge. "Do we want to convert the science into therapies that we actually would have to pay for?"

Trusheim spoke at the Biotechnology Innovation Organization (BIO) meeting in San Francisco, California, on 6-9 June, which featured much discussion about how society will pay for the rising costs of new drugs. At the American Society of Clinical Oncology meeting in Chicago, Illinois, on 3-7 June, dozens of talks and abstracts focused specifically on the growing cost of cancer care. Cancer drugs that unleash the power of the immune system cost up to $\$ 40,000$ per month.

Gene therapies that are close to US approval include treatments for haemophilia B, sicklecell anaemia and the neurodegenerative disease cerebral adrenoleukodystrophy. A therapy under development at Spark Therapeutics in Philadelphia, Pennsylvania, for a type of 
- blindness is considered the most advanced. Many of the treatments deliver corrective genes using a modified virus that is considered safer than vectors used in earlier attempts. But many of the target disorders are rare, limiting the population that can be treated. And there are often no previously approved drugs that work similarly, removing the pressure on companies to lower their prices.

Such therapies could cost $\$ 1$ million per patient, estimate haematologist Stuart Orkin of Harvard Medical School in Boston, Massachusetts, and Philip Reilly, an investor with Third Rock Ventures in Boston (S. H. Orkin and P. Reilly Science 352, 1059-1061; 2016). Reilly co-founded Cambridge-based Bluebird Bio, which is working on several of the gene therapies that are close to market.

That's the same price as Glybera, the gene therapy given the green light by European regulators in 2012, which has been taken by only one person so far. Experts attribute this low uptake to the high price and to doubts about its efficacy. If newer gene therapies are to do better, they will have to produce convincing data that they are worth the money, Trusheim says.

For medicines that are already approved, one increasingly popular solution is a deal between insurers and drug companies that ties payments to how well medicines perform. Last November, for example, Boston-based
Harvard Pilgrim Health Care, a major New England insurer, announced that it will cover treatment for its clients with Repatha (evolocumab), one of a new class of cholesterollowering medication that is made by Amgen and costs $\$ 14,000$. But if patients don't reach pre-agreed cholesterol levels, or if Harvard Pilgrim ends up paying more than it has budgeted for, Amgen will refund the insurer.

"Advances in
science are
presenting
asocial
affordability
question like
never before."
Networks set up by insurance companies to gather and share data from health centres make such deals possible, says Michael Sherman, chief medical officer at Harvard Pilgrim. And they are on the rise around the world: one study found 'pay-for-performance' deals across 14 countries in 2013, predominantly in Europe and the United States, but also in middle-income countries such as China and Brazil.

These deals may work for some conditions, such as haemophilia B, for which several drugs might be approved. But for others, such as adrenoleukodystrophy, only one company is developing a product, so there won't be the incentive for companies to negotiate, Trusheim says.

At the BIO meeting, investors and economists discussed a range of alternative solutions, including the medical equivalent of a mortgage or annuity, in which insurance companies or governments might spread the cost of a onetime treatment over many years, as long as a patient continues to benefit from it. One complication of such arrangements in the United States is that patients often move between insurers, so it is unclear who would continue to make these payments on a patient's behalf.

The difficulties of paying for the fruits of the biotechnology revolution are something that governments are already struggling with. The state of Arkansas last year settled a lawsuit filed by three people who said they had been denied access to the $\$ 300,000$ cystic fibrosis drug Kalydeco (ivacaftor) because of the cost. And in April, the Japanese government imposed a 50\% price cut on a new hepatitis $\mathrm{C}$ treatment, Sovaldi (sofosbuvir). A US federal judge in Seattle, Washington, ruled on 27 May that states cannot delay treatment with Sovaldi, which costs up to $\$ 84,000$, because of price concerns.

But those working on gene therapy are confident that a solution is out there. "Let's say that a gene therapy that really made a world of difference in the life of a small child should cost a million dollars for one event," Reilly says. "I can think of many things in medicine that cost that much or more, and we don't think twice about that." 


\section{CORRECTION}

The News story 'Gene therapies pose million-dollar conundrum' (Nature 534, 305-306; 2016) should have said that cancer drugs that unleash the power of the immune system cost up to $\$ 40,000$ per month, not per year. 